\title{
ЦЕННОСТНЫЕ ОСНОВЫ ГРАЖДАНСКО-ПРАВОВОГО РЕГУЛИРОВАНИЯ: ФОРМАЛЬНОЕ РАВЕНСТВО И СВОБОДА ВОЛИ КАК ПРЕДПОСЫЛКИ ДИСПОЗИТИВНОСТИ И ДОЗВОЛЕНИЯ
}

\section{VALUE FOUNDATIONS OF CIVIL REGULATION: FORMAL EQUALITY AND FREE WILL AS PREREQUISITES FOR DISPOSITIVENESS AND PERMISSION}

R. Ushakov

Summary. The article explores a number of controversial aspects of civil law permissions and dispositiveness. Based on the analysis of civil law, the provisions of the civilistic, theoretical and philosophical legal doctrine, the author, through the prism of an activity-dogmatic approach, reveals the key importance of the categories of free will and formal equality in determining the essence and content of the permissible method of civil law regulation. It is argued that the proper implementation of these legal values ensures the stable functioning of civil circulation; substantiates the need for formalization of civil law permission as a starting point of civil law in Art. 1 Civil Code of the Russian Federation.

Keywords: dispositivity, civil law method, dispositive method of legal regulation, authorization, permissible method of legal regulation, formal equality, free will, autonomy of will, civil circulation.

\author{
Уиаков Руслан Михайлович \\ Саратовская государственная юридическая \\ академия \\ rafikov.ruslan@list.ru
}

Аннотация. В статье исследуется ряд дискуссионных аспектов гражданско-правового дозволения и диспозитивности. На основе анализа гражданского законодательства, положений цивилистической, теоретико- и философско-правовой доктрины автором сквозь призму деятельностно-догматического подхода раскрывается ключевое значение категорий свободы воли и формального равенства в определении сущности и содержания дозволительного способа гражданско-правового регулирования. Аргументируется, что надлежащая реализация данных правовых ценностей обеспечивает устойчивое функционирование гражданское оборота; обосновывается необходимость формализации гражданско-правового дозволения в качестве исходного положения гражданского права в ст. 1 ГК РФ.

Ключевые слова: диспозитивность, гражданско-правовой метод, диспозитивный метод правового регулирования, дозволение, дозволительный способ правового регулирования, формальное равенство, свобода воли, автономия воли, гражданский оборот.
Д испозитивность - отличительный признак гражданско-правового метода. Именно в диспозитивном гражданско-правовом методе, а также в принципах, закрепленных в ст. 1 ГК РФ, обозначена ключевая идея гражданского права как совокупности правовых норм, определяющих и опосредующих имущественные, личные неимущественные и корпоративные отношения на началах юридического равенства участников гражданских правоотношений, в условиях обеспечения автономии их воли. Диспозитивность предоставляет участникам гражданских правоотношений возможность: 1) приобретать, изменять и прекращать права и обязанности; 2) осуществлять гражданские права и распоряжаться ими по своему усмотрению (реализация правомочий, отказ от прав, их отчуждение); 3) осуществлять защиту прав, выбирать ее форму и способ, размер ответственности (П.А. Гордеев) [6, с. 79].

Своеобразие метода гражданского права предопределяет особое соотношение правовых средств, составляющих специфику каждого конкретного способа правового регулирования (дозволение, запрещение, обязывание), которые, в свою очередь, имеют дифференцированное значение в регулировании гражданских правоотношений. По существу, способ - это действия по воплощению метода в жизнь, являющиеся такими проявлениями человеческой воли, которые определены в нормах права, а не конкретным лицом, их совершающим. Дозволение же является ведущим способом правового регулирования в структуре гражданско-правового метода, выполняющим, на наш взгляд, важнейшую функцию по поддержанию стабильности гражданского оборота. Очевидно, что именно дозволительный способ правового регулирования наиболее полно выражает сущность гражданско-правового метода.

В этой связи полагаем, что в настоящее время, в условиях масштабного реформирования гражданского законодательства [11], наиболее концентрированно выражающего свободу индивидов действовать своей волей и в своем интересе, исследование юридических аспектов дозволительного способа гражданско-правового регулирования приобретает особо востребованный и актуальный характер. Думается, правильное 
понимание и применение гражданско-правового дозволения, выступающего правовой формой отношений, составляющих предмет гражданского права, является ключом для устойчивого развития товарного оборота и, в конечном итоге, процветания общества. Изложенное, на наш взгляд, позволит ускорить решение ряда значимых для цивилистики проблем: соотношения частных и публичных начал в гражданском праве, дихотомии диспозитивных и императивных гражданско-правовых норм, определения границ принципа свободы договора, понимания взаимосвязи и роли запретов, обязываний и дозволений в регулировании гражданско-правовых отношений и др.

В теоретико-правовой доктрине утвердилось, что в самом общем виде сущность дозволения заключается в предоставлении лицам права на свои собственные активные действия (С. С. Алексеев) [2, с. 225], свободы в выборе варианта собственного поведения (К.Е. Игнатенкова) [8, с. 34]. С позиции инструментальной концепции права, весьма распространенной в современной юриспруденции, дозволение безусловно относится к правовым средствам, то есть к «совокупности правовых установлений (инструментов), с помощью которых удовлетворяются интересы субъектов права и обеспечивается достижение социально полезных целей» (А. В. Малько, К.В. Шундиков) [14, с. 67]. Гражданско-правовое дозволение в данной системе координат занимает место стимулирующих средств правового регулирования, поскольку оно побуждает личность на позитивное, поощряемое правом и обществом поведение, либо на нейтральные, по социальной оценке, действия.

На наш взгляд, руководствуясь деятельностно-догматическим подходом, развиваемым в диссертационном исследовании О.М. Родионовой [19], под гражданско-правовым дозволением следует понимать: а) способ правового регулирования (объективный критерий) и б) форму правовой деятельности, сущность которой заключается в гарантированной гражданским законодательством свободе субъектов гражданского права выбирать вариант собственного поведения, что основывается на их волевых действиях, осуществляемых с целью удовлетворения своих потребностей и интересов посредством приобретения, изменения и прекращения гражданских прав, свобод и обязанностей (субъективный критерий). Воплощение данной деятельности возможно посредством применения частно-автономных ненормативных регуляторов (в форме договоров, односторонних сделок, решений собраний) [19, с. 14]. Вместе с тем полагаем, что понимание содержания и структуры гражданско-правового дозволения находится в сфере философии права, в области правопонимания и правосознания, что требует исследования его различных аспектов в субстанциональных свойствах. Необходимо исходить из аксиологического анализа категорий формального равенства и свободы как всеобщих ценностей и принципов права, имманентно образующих сущность анализируемого явления.

Во-первых, руководствуясь ключевым положением концепции правопонимания В.С. Нерсесянца: «право это нормативная форма выражения свободы посредством принципа формального равенства людей в общественных отношениях» $[16$, с. 11], следует заключить, что гражданско-правовое дозволение как способ правового регулирования, отражающий определенную степень свободного усмотрения индивида, исходит из необходимости существования и реального обеспечения формального (юридического) равенства, мыслимого, прежде всего, как признаваемый государством паритет индивидов-субъектов права в предоставлении и эквивалентном объеме их гражданской правоспособности (абстрактной возможности иметь гражданские права и нести обязанности), закрепленной в объективном праве (ст. 17 ГК РФ); при этом логично, что гражданская правоспособность юридических лиц является производной по отношению к гражданской правоспособности физических лиц, а потому допустима сравнительная ограниченность первой в формате специальной правоспособности, содержание которой устанавливается учредителями юридического лица (ч. 1 ст. 49 ГК РФ).

Однако рассматриваемое всеобщее правовое начало одновременно предполагает, что объем приобретаемых участниками гражданских правоотношений реальных, конкретных субъективных прав и свобод будет неравным, поскольку фактически люди не являются равными по биологическим, экономическим, социальным и иным признакам. В этом смысле будет проявляться применение «одинакового масштаба», равной меры права как всеобщей формы к «различным людям» (В.И. Ленин) [13, с. 93], что в измерении гражданского права корректируется, приобретает специфическую функцию - уравновесить стороны в их гражданских правах, свободах и обязанностях, смягчить фактически существующее неравенство переговорных возможностей посредством пропорционального усиления слабой стороны договора (Е. В. Вавилин) [4]. Иными словами, следует заключить, что гражданско-правовое дозволение - лишь возможность, которая в процессе правовой деятельности становится действительностью, поскольку само оно, являясь правовым средством, не создает и не обеспечивает фактической возможности, а только опосредует ее реализацию.

Скорректировать и в перспективе снять существующее противоречие между юридическим равенством и фактическим неравенством имеет своей ключевой целью социалистическая правовая система, основными 
способами правового регулирования которой выступают запреты и обязывания. Однако следует констатировать, что в современную эпоху, в условиях функционирования в России рыночной экономики уравнительное распределение материальных благ сведено к необходимому минимуму в рамках мер государственного социального обеспечения, а потому на первый план в качестве ключевой цели гражданско-правовой политики (Е.В. Вавилин, М.Ю. Челышев) [5] выходит обеспечение исключительно формального равенства участников гражданских правоотношений (ч. 1 ст. 1, ч. 1 ст. 2 ГК РФ) как необходимого условия нормального функционирования гражданского оборота и гарантии реализации дозволения - основного регулятивного звена в гражданско-правовом механизме, наиболее полно отражающего индивидуально-ориентированный характер существующего права, в основе которого - приоритет прав и свобод человека и гражданина (ст. 2, 17 Конституции России 1993 г.).

Во-вторых, формальное равенство как необходимое условие функционирования современного права является также одной из базовых гарантий свободы - центральной морально-правовой категории, образующей составной элемент содержания дозволительного способа гражданско-правового регулирования. Свобода, будучи философско-правовой категорией [17, с. 501], является объектом сложным как для понимания, так и для практического воплощения в отраслях, институтах и нормах права. Думается, следует согласиться с мнением В.С. Нерсесянца, что «другой формы бытия и выражения свободы в общественной жизни людей, кроме правовой, человечество до сих пор не изобрело» [16, с. 14]. Как справедливо указывает Д.А. Керимов, «только в условиях свободы личность получает возможности для раскрытия и развития своих способностей и талантов, для проявления инициативы и волевых устремлений» $[10$, c. 443].

В свою очередь, дозволения и запреты, выраженные в нормах права, оформляют свободу в общественном бытии, ее пределы и границы с несвободой на соответствующей ступени исторического развития. «Ограничивая свободу каждого известными пределами, закон обеспечивает ему беспрепятственное и спокойное пользование своими правами, т.е. гарантирует ему свободу внутри этих пределов. Свобода каждого человека простирается лишь до той границы, от которой начинается свобода других людей» (И. А. Ильин) [9, с. 96]. Тем самым право, независимо от формы его выражения, всегда выступает определенным ограничителем человеческой свободы, его сущности имманентно некоторое сужение свободного поведения индивида в рамках правоотношения. Виды гражданско-правового дозволения - права, свободы и законные интересы - являются одновре- менно мерами свободы, поскольку они устанавливают ее объем, ограничением которого выступают запреты и обязывания, определяющие границы данной свободы (при этом само гражданско-правовое дозволение в определенном смысле также ограничивает фактическую свободу субъектов гражданского права).

Между тем далеко не только и не столько право выступает ограничителем человеческой свободы. Мощнейший регулятор поведения человека - мораль имеет определяющее значение в регулировании общественных отношений. Нередко сочетание права и морали в результате санкции государства образует синтез в форме правовых обычаев, что в современном гражданском праве (ранее - под названием обычаев делового оборота) получило прямое формальное отражение в ст. 5 ГК РФ. Такая морально-правовая ценность, как добросовестность, позволяет противодействовать обходу закона и иным формам злоупотребления правом (ст. 10 ГК РФ) и тем самым ограничить произвол субъектов гражданского оборота, гарантировать его нормальное функционирование.

В этой связи следует констатировать, что дозволения и запреты как таковые (то есть как социальные регуляторы в форме норм морали) существовали в обществе всегда. Исторически первым способом регулирования поведения человека был неправовой запрет (К.Е. Игнатенкова) [8, с. 34], а соответствующие ему дозволения мыслились лишь в его контексте, носили производный характер. Права самостоятельного значения не имели, выступая в качестве оборотной стороны обязанностей. Однако по мере общего прогресса человечества, развития экономических отношений, обособления частной собственности и формирования классовой дифференциации, появления государства и права самые важные, типичные, то есть устоявшиеся в общественной практике дозволения приобретали юридическую форму, опосредуясь в нормативно-правовом материале, становились юридически значимы для общества, а потому брались под охрану государством, которое с определенного момента было способно обеспечить их реализацию посредством применения принудительной силы. «Право становится той социальной формой, при помощи которой дозволениям и запретам придается необходимая определенность и более высокая нормативность (обобщенность), ... а также сообщаются другие правовые свойства, в том числе общеобязательность» (С.С. Алексеев) [1, с. 252]. По мере распространения указанного процесса постепенно возрастает степень свободы общества в целом. «Процесс трансформации преимущественно запретительной системы социального регулирования в запретительно-дозволительную ознаменовал собой некую «смену эпох», становление общества на новую ступень развития» (К. Е. Игнатенкова) [8, с. 34]. 
Иллюстрирует вышеизложенное пример эволюции института брака в римском праве. Как известно из анализа историко-правовых источников, в ранний период древнеримской истории господствовал патриархальный брак типа cum manu, основанный на всевластии мужа (или его paterfamilias) по отношению к жене, юридический статус которой был приравнен к вещному (он мог истребовать ее с помощью виндикационного иска). Последняя не обладала свободой, поскольку не была юридически равна мужу, являясь объектом, а не субъектом права (в частности, не могла по своему усмотрению прекратить брачные отношения, на что имел право лишь муж). Постепенно, после принятия Законов XII таблиц, его вытеснил партнерский брак типа sine manu, в рамках которого власть мужа (manus) не распространялась на жену - она состояла в брачном сожительстве рядом с мужем как существо юридически свободное и самостоятельное. Отныне семейные отношения перестали представлять собой лишь разновидность вещных, обрели некоторую автономию. Ключевым с точки зрения юридической свободы является то, что брак sine manu заключался по свободному соглашению супругов и мог быть прекращен односторонним волеизъявлением любого из них (repudium) вне зависимости от содержания причин развода (И. А. Покровский) [18, с. 450-454].

Обобщая, следует заключить, что фундаментальное значение свободы для гражданского права состоит в том, что она, объективируясь в правовых формах, а конкретно - в дозволениях, закрепленных в управомочивающих гражданско-правовых нормах, является предпосылкой для удовлетворения потребностей и реализации интересов лица как участника гражданского оборота. «Начальное равенство и дальнейшая свобода - вот формула дозволения» (К.Е. Игнатенкова) [8, с. 36]. Гражданско-правовое дозволение заключает в себе свободу, которая, однако, не является абсолютно безграничной - поскольку дозволение - явление правовое, пределом, ограничением ей служат диалектически связанные с ней гражданско-правовой запрет и обязывание, поддерживаемые таким социальным регулятором, как мораль.

В-третьих, поскольку сущностная основа гражданско-правового дозволения состоит в возможности свободного, осознанного выбора лицом варианта собственного поведения, то есть свободы определения его содержания, то волевой момент занимает значительное место в понимании данной категории. Следует согласиться с тем, что «волевой характер права обусловлен именно тем, что право - это форма свободы людей, т.е. свобода их воли» (В.С. Нерсесянц) [16, с. 13]. Воля выступает необходимым компонентом любой, в том числе гражданско-правовой, деятельности: свобода, выраженная в абстрактных нормах гражданского права, получает реальное воплощение в действительности в форме деятельности, внутренней движущей силой которой является целенаправленная сознательная воля конкретных физических лиц, в своей исходной сущности обусловленная их потребностями и интересами как объективно-субъективными детерминантами поведения личности (С. А. Бурмистрова) [3].

В современном частном праве в наиболее полном виде юридическое обеспечение свободы (автономии) воли лица выражено в основополагающем исходном начале гражданского права - принципе свободы договора (п. 1. ст. 1, ст. 421 ГК РФ), сущность которого состоит в юридически обеспеченной возможности субъектов права вступать в социальные взаимодействия, опосредуемые гражданским законодательством. Аспектами его проявления, в частности, являются: а) свобода заключать либо не заключать договор - недопустимо понуждение к заключению договора, за исключением случаев, когда обязанность одной из сторон заключить договор предусмотрена законом (ст. 445, ст. 426 ГК РФ) или в силу добровольно принятого обязательства (ст. 429 ГК РФ); б) свобода в выборе контрагента по договору; в) свобода в выборе конкретного вида либо разновидности договора, как предусмотренного (поименованного), так и не предусмотренного (не поименованного) законом или иными нормативными актами, а также право заключать договоры, содержащие элементы различных договоров, то есть смешанный договор (п. 2, 3 ст. 421 ГК); г) свобода в выборе условий заключаемого ими договора (ст. 432 ГК РФ), что обусловлено диспозитивным характером большинства норм, регулирующих отдельные виды договоров. При этом сторонам предоставлена возможность руководствоваться свободой договора не только на стадии установления отношений, но и на стадии их изменения (В.А. Кочев) [12, с. 50]. Принцип свободы договора отражает квинтэссенцию дозволительной природы гражданского права, выступая в качестве примера общего дозволения - сложной юридической конструкции более высокого уровня, чем простые дозволения, образующей качественно иную абстракцию - общедозволительный тип правового регулирования (С. С. Алексеев) $[1$, с. 312$]$.

Однако представляется, что придание гипертрофированно преувеличенной роли фактору свободы воли в механизме гражданско-правового регулирования (что нередко следует из либеральной риторики в аспекте предоставления субъектам гражданского права все больших прав при необоснованном сокращении обязанностей) чревато постепенным переходом в субъективный идеализм и волюнтаризм, что нецелесообразно, так как недостаточный учет объективных факторов общественного развития влечет непосредственную угрозу нормальной работе данного механизма. Думается, 
не теряет актуальности утверждение, высказанное основоположником диалектического материализма Ф. Энгельсом вслед за Г.В.Ф. Гегелем: «свобода есть познанная необходимость» [15, с. 116]. Выражением подобной объективной необходимости в частном праве, как было научно обосновано В.С. Емом, выступает категория обязанности [7, с. 9], которая имплицитно содержит в себе запрет. Она является своеобразным уравновешивающим «противовесом» корреспондирующей ей категории субъективных прав - одной из форм выражения гражданско-правового дозволения - и служит обеспечению последней. При этом тот факт, что большинство норм гражданского права - запретительные и обязывающие $[19$, с. 68], не умаляет того, что основополагающая, приоритетная роль в формах проявления его метода принадлежит именно управомочивающим нормам, являющимся формой выражения дозволительного способа правового регулирования.

Руководствуясь содержанием исходного правила гражданского права, которое, как следует из диссертации О.М. Родионовой, можно реконструировать следующим образом: «Если лицо относится к субъектам гражданского права, то оно имеет право действовать по своему усмотрению без намерения причинения вреда другим, иначе у него возникает обязанность восстановить нарушенное положение» [19, с. 70], следует заключить, что возможность выбирать и определять содержание своего поведения, предоставленная субъекту гражданского права и выраженная в управомочивающих нормах, ограничена общим запретом намеренного причинения вреда другим и сопутствующей обязанностью (которая также содержит имплицитно запрет) возместить его в случае совершения гражданского пра- вонарушения (деликта) (ст. 1064 ГК РФ), что отражает диалектическое единство дозволений, запретов и обязываний в гражданском праве.

Таким образом, обобщая вышеизложенное, следует заключить, что исследованные общеправовые ценности являются необходимыми предпосылками и гарантиями реализации гражданско-правового дозволения, выраженного в управомочивающих нормах гражданского права, составляют его содержание как цивилистической категории, заключающей в себе определенную меру свободы. Формальное равенство выступает условием деления общества на равноправных участников гражданского оборота. Свобода воли имеет внешнее проявление в обеспеченной объективным правом возможности совершать юридически значимые действия, прежде всего - заключать сделки посредством выражения собственного волеизъявления, что, однако, ограничивается юридической конструкцией гражданско-правовой обязанности (и запрета) как формы проявления общественной необходимости и поддерживается таким социальным регулятором, как мораль. Полагаем, что преодоление ряда гражданско-правовых проблем требует дальнейшего исследования дозволения как ключевого цивилистического способа правового регулирования с последующим его обособленным закреплением в качестве исходного положения гражданского права в ст. 1 ГК РФ.

Выражаем благодарность кандидату юридических наук, доценту, профессору кафедры гражданского права Саратовской государственной юридической академии Гаврилову Владимиру Николаевичу.

\section{ЛИТЕРАТУРА}

1. Алексеев С. С. Общие дозволения и общие запреты в советском праве // Собрание сочинений. Т. 2. 2010. М.: Статут. 471 с.

2. Алексеев С. С. Теория права. Издание второе. М.: Издательство БЕК, 1995. 320 С.

3. Бурмистрова С. А. 06 объективном и субъективном в правовой природе интереса // Вестник ЮУрГУ. Серия: Право. 2018. № 1. С. 54-59.

4. Вавилин Е. В. Осуществление и защита субъективных прав слабой стороны в гражданском правоотношении // Российское правосудие. М., 2007. № 6. C. 31-37.

5. Вавилин Е.В., Челышев М. Ю. Гражданско-правовая политика // Вестник СГЮА. 2012. № 3 (86). 125-132.

6. Гордеев П. А. Диспозитивность в регулировании гражданских правоотношений: теоретико-методологический анализ // Российское право: 06разование. Практика. Наука. 2018. № 4 (106). С. 79-86.

7. Ем В. С. Категория обязанности в советском гражданском праве (вопросы теории): дис. ... канд. юрид. наук. М., 1981. 209 с.

8. Игнатенкова К. Е. Дозволение как способ правового регулирования: дис. ... канд. юрид. наук. Саратов, 2006. 229 с.

9. Ильин И. А. Общее учение о праве и государстве (фрагменты) // Правоведение. 1992. № 3. С. 93-99.

10. Керимов. Д. А. Методология права: Предмет, функции, проблемы философии права. 2-е изд. М.: Аванта, 2001.560 с.

11. Концепция развития гражданского законодательства Российской Федерации // Вестник ВАС РФ. № 11. 2009.

12. Кочев В.А. К вопросу о сущности договорной свободы. // Юридическая наука и правоохранительная практика. 2010. № 2 (12). С. 50 -54.

13. Ленин В. И. Полное собрание сочинений. Т. 33. Издание пятое. М.: Издательство политической литературы, 1969. 433 с.

14. Малько А.В., Шундиков К. В. Цели и средства в праве и правовой политике. Саратов, 2003. 296 с.

15. Маркс К., Энгельс Ф. Сочинения. Том 20. Издание второе. М.: Государственное издательство политической литературы, 1961. 828 с. 
16. Нерсесянц В.С. Философия права. Учебник для вузов. М.: Норма. 2005. 656 с.

17. Новая философская энциклопедия. Т. 3. М.: Мысль, 2010. 692 с.

18. Покровский И. А. История римского права. СПб.: Издательско-торговый дом «Летний сад», 1999.531 с.

19. Родионова 0. М. Правовые формы реализации волевых отношений в механизме гражданско-правового регулирования: дис. ... докт. юрид. наук. М., 2017. 502 c.

(c) Ушаков Руслан Михайлович ( rafikov.ruslan@list.ru ).

Журнал «Современная наука: актуальные проблемы теории и практики»

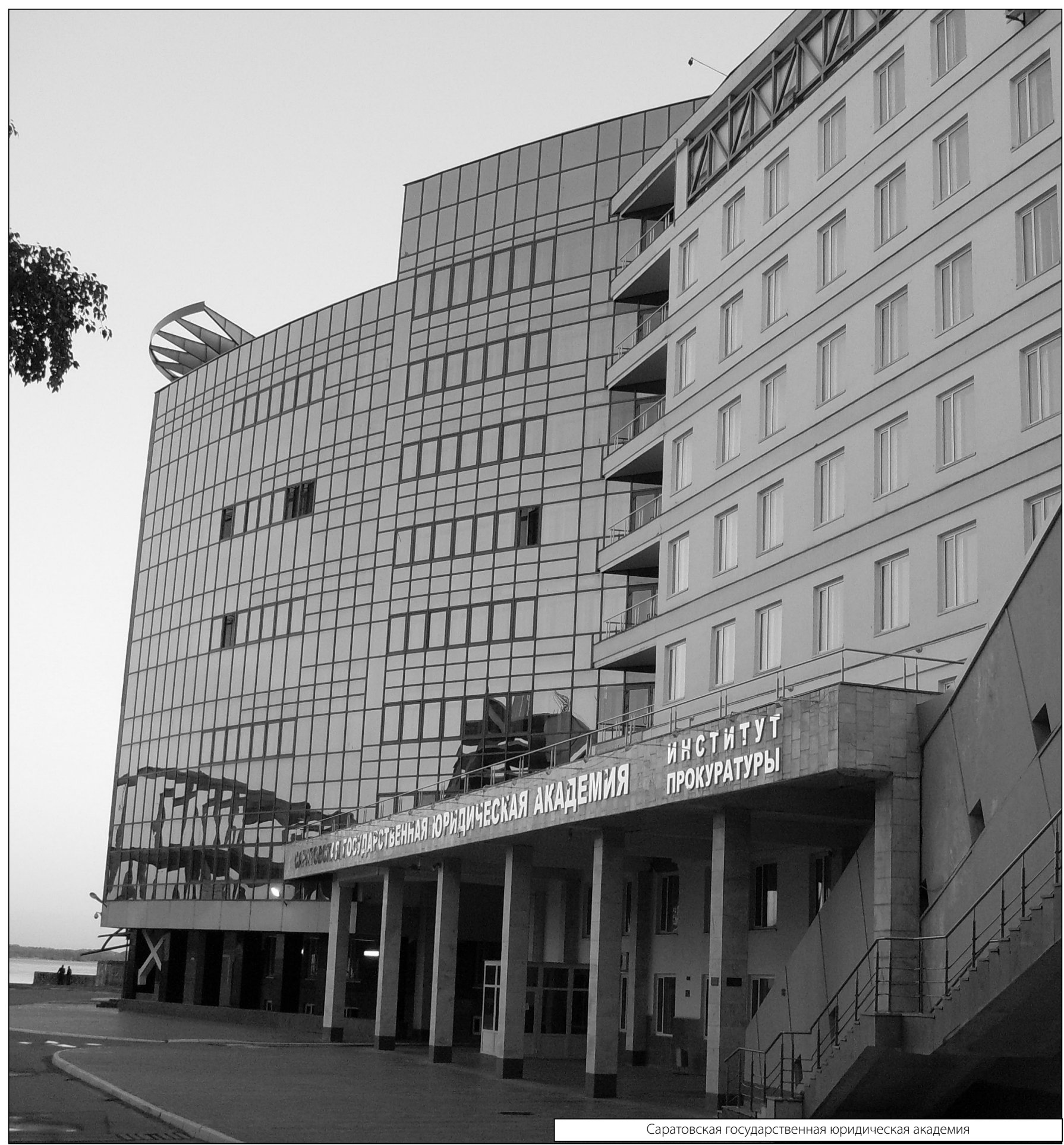

